\title{
Ventilatory dependency after cardiovascular surgery
}

\author{
Sudish C. Murthy, MD, PhD, alejandro C. Arroliga, MD, ${ }^{b}$ Peter A. Walts, MD, ${ }^{\text {a }}$ Jingyuan Feng, MS, ${ }^{c}$ \\ Jean-Pierre Yared, MD, ${ }^{d}$ Bruce W. Lytle, MD, ${ }^{a}$ and Eugene H. Blackstone, MD ${ }^{\mathrm{a}, \mathrm{c}}$
}

丹 Supplemental material is available online.
From the Departments of Thoracic and Cardiovascular Surgery, ${ }^{\mathrm{a}}$ Pulmonary, Allergy, and Critical Care Medicine, ${ }^{\mathrm{b}}$ Quantitative Health Sciences, ${ }^{\mathrm{c}}$ and Cardiothoracic Anesthesia, ${ }^{\mathrm{d}}$ Cleveland Clinic, Cleveland, Ohio.

Received for publication Nov 28, 2006; revisions received Feb 23, 2007; accepted for publication March 8, 2007.

Address for reprints: Sudish C. Murthy, $\mathrm{MD}, \mathrm{PhD}$, Department of Thoracic and Cardiovascular Surgery, Cleveland Clinic, 9500 Euclid Avenue/Desk F24, Cleveland, OH 44195 (E-mail: murthys1@ ccf.org).

J Thorac Cardiovasc Surg 2007;134:484-90 $0022-5223 / \$ 32.00$

Copyright () 2007 by The American Association for Thoracic Surgery

doi:10.1016/j.jtcvs.2007.03.006
Objectives: Ventilatory dependency is a widely recognized complication of cardiovascular surgery, often leading to tracheostomy. Some risk factors for its occurrence have been documented. Less well characterized are short- and long-term outcomes. Therefore, objectives were to identify risk factors for ventilatory dependency, assess its short- and long-term outcomes, and determine impact of tracheostomy.

Methods: From January 1998 to September 2001, 12,777 patients underwent cardiovascular surgery and survived at least 72 hours. Of these patients, 704 (5.5\%) developed ventilatory dependency (cumulative intubation $>72$ hours); 185 (26\%) underwent tracheostomy. Preoperative, intraoperative, and intensive care unit admission data were used sequentially to understand predictors of ventilatory dependency. Outcomes were analyzed by time-related methods, and impact of tracheostomy was assessed using competing-risks analysis.

Results: Hemodynamic status on intensive care unit admission (low cardiac output, vasopressor use, pulmonary hypertension; $P<.0001)$ and early postoperative events (stroke, bacteremia; $P<.0001$ ) were more important than preoperative and intraoperative variables in predicting ventilatory dependency. Survival at 30 days, 1 year, and 5 years thereafter was $76 \%, 49 \%$, and $33 \%$ and was strongly associated with favorable hemodynamic status. By 28 days, $24 \%$ of patients received tracheostomy; survival at 30 days and 2 years thereafter was $74 \%$ and $26 \%$, considerably below anticipated survivals of $84 \%$ and $58 \%$.

Conclusions: Improved operative and postoperative strategies to preserve myocardial function and restore hemodynamics should decrease the prevalence of ventilatory dependency. Unfortunately, preoperative models of ventilatory dependency are too insensitive for clinical use. Tracheostomy and its outcome are also poorly predicted, highlighting the complex interaction of events altering patients' conditions before and after tracheostomy.

$\mathrm{V}$ entilatory dependency is a widely recognized complication of cardiovascular surgery, occurring in up to a fifth of patients and, in some, leading to tracheostomy. ${ }^{1-7}$ Recently, we have examined outcomes after tracheostomy in such patients, demonstrating that only a third of patients were long-term survivors, with most dying of multisystem organ failure. ${ }^{8}$ Given these findings, we were curious about predictors not only of tracheostomy, but also of ventilatory dependency in this population. Although some risk factors for ventilatory dependency have been documented, ${ }^{4,5,7,9,10}$ less characterized are short- and long-term outcomes. ${ }^{4,5,7}$ Therefore, the intent of this companion study was to focus on (1) factors associated with ventilatory dependency after cardiovascular surgery, (2) time-related outcomes of ventilatory dependency, and (3) predictors and impact of tracheostomy after ventilatory dependency.

\section{Patients and Methods \\ Patients}

Between January 1998 and September 2001, 12,836 patients underwent cardiovascular surgery at Cleveland Clinic, exclusive of heart transplantation and insertion of ventricular assist devices. Fifty-nine who died within 72 hours were excluded from the study, leaving 


\section{Abbreviations and Acronyms \\ $\mathrm{CL}=$ confidence limit \\ CTA $=$ Cardiothoracic Anesthesia registry \\ CVIR = Cardiovascular Information Registry \\ ICU = intensive care unit \\ NYHA $=$ New York Heart Association \\ STS $=$ The Society of Thoracic Surgeons}

12,777 patients. Of these, $704(5.5 \%)$ experienced ventilatory dependency (defined in text that follows), of whom 185 (26\%) underwent tracheostomy.

Patient characteristics and operative variables were extracted from the Cardiovascular Information Registry (CVIR); respiratory and hemodynamic condition on intensive care unit (ICU) admission and medications administered within 24 hours thereafter (Tables E1-A and E1-B) were extracted from the Cardiothoracic Anesthesia (CTA) registry. Data are abstracted for both registries concurrently with patient care by experienced technicians and nurses and subjected to quality control. Both databases have been approved for use in research by the Institutional Review Board of the Cleveland Clinic, with patient consent waived.

\section{Ventilatory Dependency}

All operative and ICU intubation and extubation times were recorded in the CTA database. Ventilatory dependency was defined as 72 hours or more of postoperative endotracheal intubation, starting from completion of the index operation. Of the 704 patients experiencing ventilatory dependency according to this definition, 2 populations were represented: those with early and persistent ventilatory dependency who were not extubated within the initial 72 hours $(n=395,56 \%)$ and those who had 1 or more unsuccessful extubation attempts $(n=309,44 \%)$ and ultimately accumulated at least 72 hours of endotracheal intubation. For the latter, interval between initial extubation and reintubation was calculated and used for some analyses.

Time zero for patients experiencing ventilatory dependency was the point at which they had accumulated 72 hours of endotracheal intubation. For all others, it was 72 hours after completion of their index operation.

Primary responsibility for ventilatory management, including timing of extubation and reintubation, was assumed by a dedicated group of cardiothoracic anesthesiologists and respiratory therapists under the direction of the same individual (J.P.Y.) throughout the time course of the study. Algorithms for extubation and respiratory care were standardized and followed throughout the study time frame.

\section{End Points}

Primary end points were (1) all-cause mortality and (2) tracheostomy. Vital status was obtained from the Social Security Death Index on December 6, 2005, and was available for 11,666 patients $(91 \%) .{ }^{11}$ Reliable information was considered available 6 months earlier, so a common closing date of June 6, 2005, was used for analyses. Among surviving patients, mean follow-up was $5.0 \pm$ 1.9 years; 57,603 patient-years of information were available for analyses.
Secondary end points after time zero included in-hospital stroke, renal failure, arrhythmia, sepsis, mediastinitis, and reoperation for bleeding, as defined by The Society of Thoracic Surgeons (STS; see http://www.ctsnet.org/file/rptDataSpecifications252_ 1_ForVendorsPGS.pdf).

\section{Data Analysis}

Risk factors for ventilatory dependency. A sequence of logistic regression analyses was performed to identify risk factors for ventilatory dependency, based first on preoperative factors, including intended operation, then on these variables and (1) additional operative details, (2) ICU and entry variables, and (3) interim events (Appendix E1). Variable selection used bootstrap aggregation ("bagging"). ${ }^{12,13}$ In brief, 100 data sets were obtained by random sampling with replacement, automated stepwise regression was performed, and variables with $P<.05$ were identified. Analyses included exploration of transformations of continuous variables. After aggregation of all analyses, variables appearing in $50 \%$ or more of them were selected as reliable associations.

Outcome of ventilatory dependency. Impact of ventilatory dependency was assessed by in-hospital morbidity developing after ventilatory dependency and by time-related survival. Survival was estimated nonparametrically by the Kaplan-Meier method and parametrically by multiphase hazard decomposition. ${ }^{14}$

Risk factors for death after ventilatory dependency were identified by multivariable multiphase hazard decomposition. ${ }^{14}$ Variables considered in risk factor identification are listed in Appendix E1. Bagging was used for variable selection, based on 1000 bootstrap samples, conducted as described under "Risk Factors for Ventilatory Dependency."

Impact of tracheostomy. Time of occurrence of tracheostomy in the course of ventilatory dependency was estimated nonparametrically and parametrically. Variables considered in risk factor identification are listed in Appendix E1. Bagging was used for variable selection.

To explore the interrelation of mortality and tracheostomy, we performed a competing-risks analysis for (1) death before tracheostomy, (2) recovery from ventilatory dependency, and (3) tracheostomy. Nonparametric estimates were obtained by the method of Andersen and colleagues ${ }^{15}$ and parametric estimates by numerical integration. Predicted survival after tracheostomy was estimated by calculating parametric survival curves for each patient conditional on survival to tracheostomy using the analysis of death before tracheostomy (Appendix E2 and Table E2). The average of these survival curves was compared with observed survival.

\section{Data Presentation}

Survival curves are presented using both parametric and nonparametric estimates. Confidence limits (CL) are asymmetric and equivalent to \pm 1 standard error $(68 \%)$. Tabular presentation of multivariable models is in terms of regression coefficients and their standard errors rather than odds and hazard ratios. This is in part because most continuous variables required transformation of scale, making these ratios difficult to interpret, and also because the models of survival are inherently ones of nonproportional hazards. 


\section{Results}

\section{Risk Factors for Ventilatory Dependency}

Preoperative prediction model. Ventilatory dependency gradually declined in frequency over the study period (Figure E1, $A ; P<.0001)$. Preoperative factors that predisposed patients to postoperative ventilatory dependency included higher body mass index, higher New York Heart Association (NYHA) class, chronic obstructive pulmonary disease, and any aortic procedure (Table E3). To illustrate the impact of these factors on postoperative ventilatory dependency, for a typical patient undergoing elective primary isolated coronary artery bypass grafting in 2001 (body mass index $27 \mathrm{~kg} \cdot \mathrm{m}^{-2}$, NYHA class II, blood urea nitrogen $18 \mathrm{mg} \cdot \mathrm{dL}^{-1}$, hematocrit $39 \%$, no previous myocardial infarction, no peripheral arterial disease, no preoperative heart failure, no chronic obstructive pulmonary disease), risk of ventilatory dependency is predicted to be $0.89 \%$ (CL $0.81 \%-0.97 \%$ ). In contrast, for a patient undergoing elective reoperative double valve replacement with otherwise similar characteristics (except NYHA class III or IV, hematocrit of $30 \%$, and tricuspid valve regurgitation), risk of ventilatory dependency is predicted to be $11.4 \%$ (CL 11.1\%-11.7\%).

Postoperative prediction model. When operative details, measurements made on ICU admission (including medications for the first 24 hours), and events occurring before ventilatory dependency developed were considered, almost all preoperative factors were displaced from the prediction model (Table 1). Consequently, only higher NYHA class, higher blood urea nitrogen, lower hematocrit (Figure E1, B), emergency operation, and operation performed earlier in the series remained in the postoperative prediction model.

At induction of anesthesia, patients ultimately experiencing ventilatory dependency were tachycardic (Figure 1, A) and had higher central venous pressure. The only surgical risk factor was longer cardiopulmonary bypass time, particularly beyond 2 hours (Figure E1, C). Postoperative risk factors on entry to the ICU were pulmonary hypertension and low cardiac index (Figure 1, $B$ and $C$ ). Not surprisingly, patients with ventilatory dependency required inotropic and vasoactive medications. They also were more likely to have experienced early postoperative events (before ventilatory dependency or within the first 72 hours), including bleeding necessitating reoperation, stroke, myocardial infarction, and bacteremia and sepsis.

\section{Outcomes of Ventilatory Dependency}

Patients experiencing ventilatory dependency had high hospital morbidity (bacteremia, 159/704, 23\%; renal failure, 104/704, 15\%; stroke, 45/704, 6.4\%; myocardial infarction 4/704, 0.52\%). Hospital mortality was $30 \%$ (209/704). At 30 days, 6 months, and 5 years, survival was $76 \%, 53 \%$, and $33 \%$, respectively (Figure 2 ).
TABLE 1. Incremental risk factors for development of ventilatory dependency, based on preoperative, intraoperative, and postoperative variables

\begin{tabular}{|c|c|c|c|}
\hline Risk factor & Coefficient \pm SE & $\boldsymbol{P}$ & $\begin{array}{c}\text { Reliability } \\
(\%)^{*}\end{array}$ \\
\hline \multicolumn{4}{|l|}{ Preoperative } \\
\hline Emergency operation & $1.1 \pm 0.18$ & $<.0001$ & 88 \\
\hline Higher BUN & $0.019 \pm 0.003$ & $<.0001$ & 89 \\
\hline Lower hematocrit & $-0.057 \pm 0.0096$ & $<.0001$ & 52 \\
\hline \multicolumn{4}{|l|}{ Intraoperative } \\
\hline Use of circulatory arrest & $0.81 \pm 0.16$ & $<.0001$ & 59 \\
\hline Aortic surgery & $1.2 \pm 0.23$ & $<.0001$ & 58 \\
\hline \multicolumn{4}{|l|}{ Postoperative } \\
\hline \multicolumn{4}{|l|}{ At ICU admission } \\
\hline Higher PPA, diastolic & $0.04 \pm 0.0086$ & $<.0001$ & 68 \\
\hline Lower cardiac indext & $0.73 \pm 0.14$ & $<.0001$ & 56 \\
\hline Higher Pcv & $0.16 \pm 0.037$ & $<.0001$ & 50 \\
\hline Higher $\mathrm{FlO}_{2} \S$ & $0.73 \pm 0.095$ & $<.0001$ & 80 \\
\hline \multicolumn{4}{|l|}{$\begin{array}{l}\text { Medications administered } \\
\text { first } 24 \mathrm{~h} \\
\text { postoperatively }\end{array}$} \\
\hline Milrinone & $1.01 \pm 0.12$ & $<.0001$ & 98 \\
\hline Dobutamine & $1.04 \pm 0.22$ & $<.0001$ & 53 \\
\hline Norepinephrine & $0.61 \pm 0.10$ & $<.0001$ & 50 \\
\hline Phenylephrine & $1.01 \pm 0.21$ & $<.0001$ & 51 \\
\hline Epinephrine & $0.77 \pm 0.11$ & $<.0001$ & 92 \\
\hline \multicolumn{4}{|l|}{$\begin{array}{l}\text { Early postoperative } \\
\quad \text { events (within } 72 \mathrm{~h} \text { ) }\end{array}$} \\
\hline Stroke & $2.3 \pm 0.23$ & $<.0001$ & 99 \\
\hline $\begin{array}{l}\text { Bacteremia or } \\
\text { septicemia }\end{array}$ & $2.3 \pm 0.41$ & $<.0001$ & 56 \\
\hline $\begin{array}{l}\text { Reoperation for } \\
\text { bleeding }\end{array}$ & $1.4 \pm 0.15$ & $<.0001$ & 99 \\
\hline
\end{tabular}

BUN, Blood urea nitrogen; $\mathrm{FIO}_{2}$ inspired oxygen fraction; $I C U$, intensive care unit; $P C V$, central venous pressure; $P P A$, pulmonary artery pressure; $S E$, standard error. *Frequency of occurrence in bootstrap bagging. $† 3 /$ cardiac index, inverse transformation. $\ddagger(\text { Central venous pressure } / 10)^{2}$, squared transformation. $\S\left(\mathrm{FiO}_{2} / 60\right)^{2}$, squared transformation.

Risk factors for early mortality after ventilatory dependency were dominated by those relating to cardiac, rather than pulmonary, dysfunction (Table 2). These included low cardiac index (Figure E2, A), hypotension, metabolic acidosis (Figure E2, $B$ ), and use of vasopressin at initial ICU admission. Although overall survival of patients with early and persistent ventilatory dependency was similar to that of those who had 1 or more unsuccessful extubation attempts $(P[\log -r a n k]=.8)$, the longer the interval before reintubation, the higher the risk of death. Older age, chronic renal failure, and early carbon dioxide retention dominated the late hazard phase.

\section{Impact of Tracheostomy}

Use of tracheostomy peaked about 9 days after the onset of ventilatory dependency and declined rapidly thereafter, with 

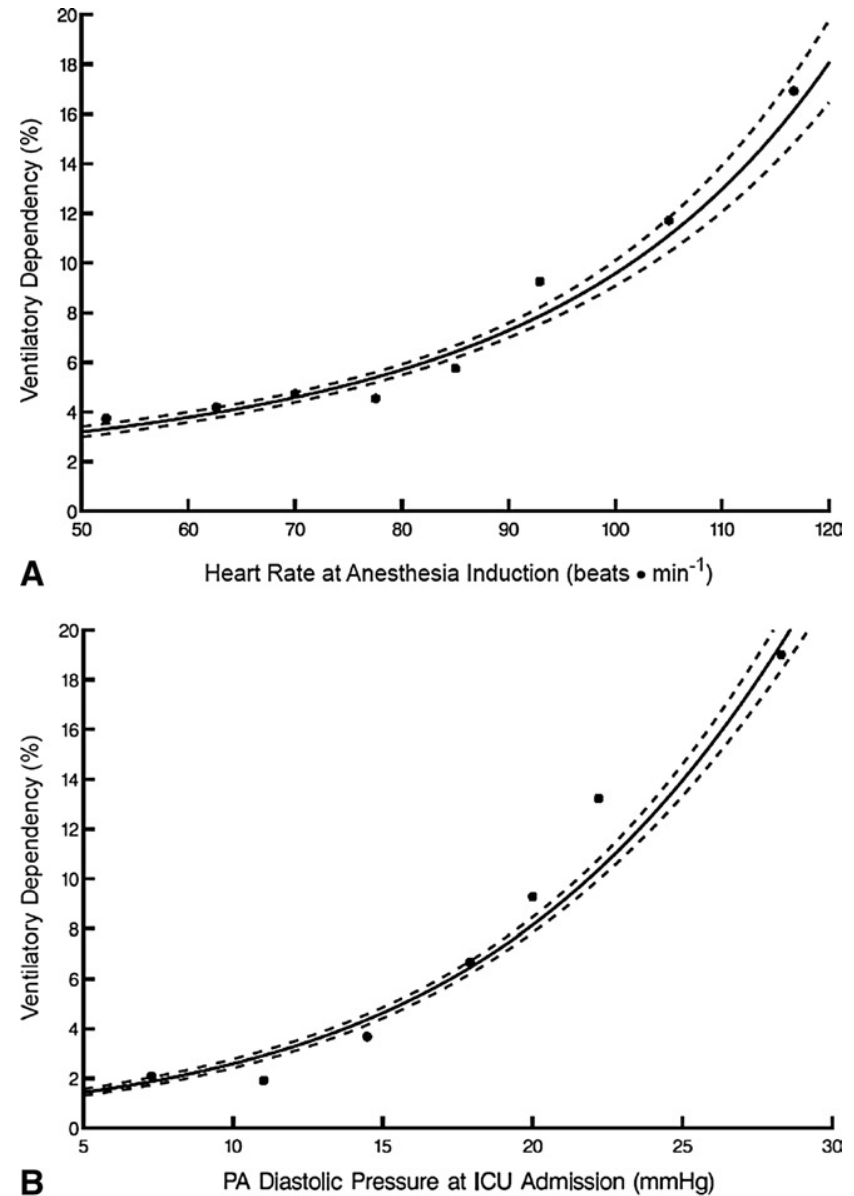

B

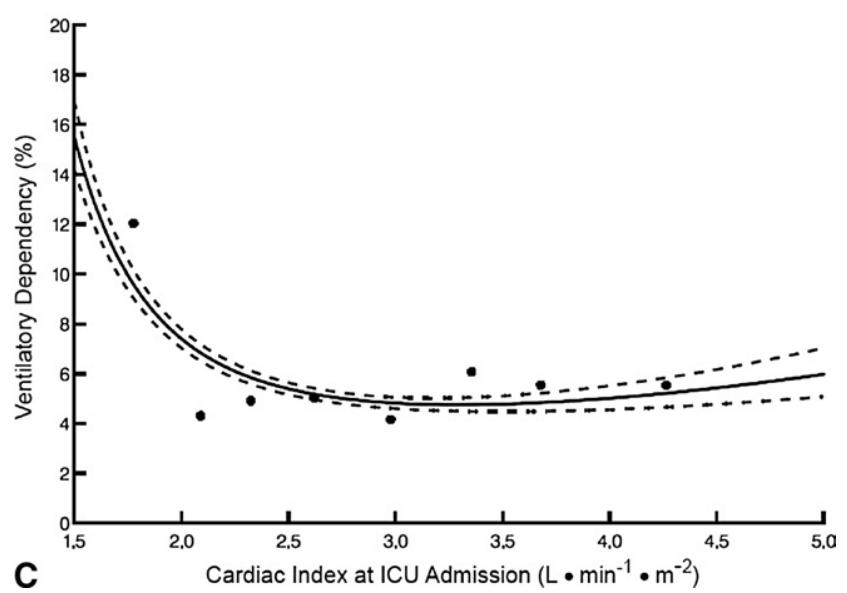

Figure 1. Relationship of various factors to postoperative ventilatory dependency. Closed circles represent summary data, and solid lines are trend lines enclosed within $68 \%$ confidence limits ( \pm 1 standard error). A, Heart rate at anesthesia induction. $B$, Pulmonary artery (PA) diastolic pressure at intensive care unit (ICU) admission. C, Cardiac index at ICU admission.

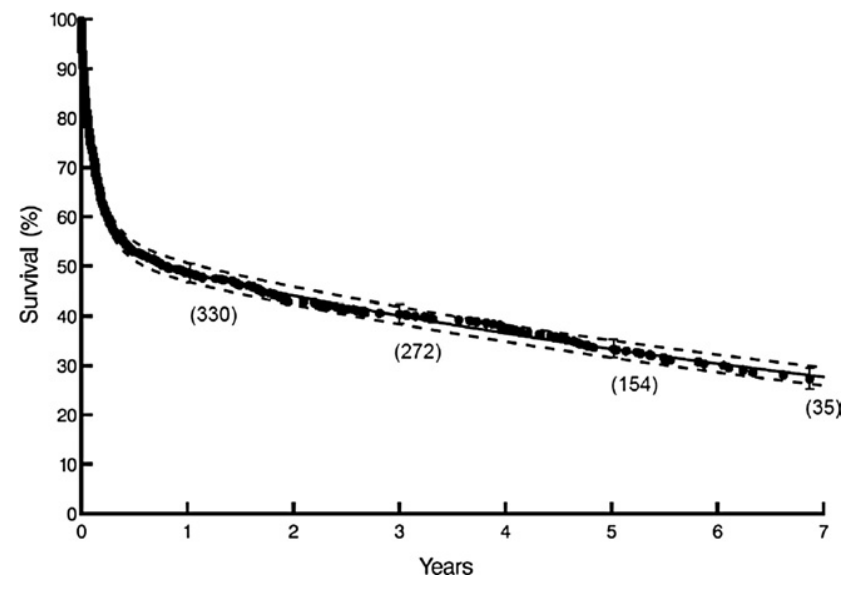

Figure 2. Survival of patients experiencing ventilatory dependency. Symbols represent deaths, vertical lines are $68 \%$ CLsequivalent to \pm 1 standard error, and numbers in parentheses are patients remaining at risk. Solid lines enclosed within dashed CLs are parametric estimates. Time zero is after 72 cumulative hours of intubation after cardiovascular surgery.

$24 \%$ of all patients in ventilatory dependency receiving tracheostomy by 28 days (Figure 3). Risk factors for tracheostomy included older age (Figure E3), chronic obstructive pulmonary disease, pre-existing renal insufficiency, and longer cardiopulmonary bypass time (Table 3 ).

Observed survival after tracheostomy was $74 \%$ at 30 days and $26 \%$ at 2 years. ${ }^{8}$ In contrast, predicted survival for these patients based on a competing-risks model that included only preoperative, operative, and ICU admission variables (Appendix E2) was $84 \%$ at 30 days and $58 \%$ at 2 years (Figure 4).

\section{Discussion}

\section{Principal Findings}

Ventilatory dependency, when present, complicates recovery from cardiovascular surgery and is associated with high early mortality. Risk factors representing the dynamic evolution of the patient's condition become increasingly more sensitive to this event as it approaches. Specifically, interim events and the condition of the patient in the immediate postoperative period are more important than operative procedure and preoperative patient characteristics.

For most of these patients, ventilatory dependency occurs in the presence of a systemic syndrome, of which heart dysfunction appears to be a central component. We speculate that as myocardial function improves and hemodynamics stabilize, early ventilatory dependency abates, leading to patient survival. However, this is not a universal occurrence; ability to withstand the initial insult after surgery is not the same among patients, because factors such as age, chronic renal insufficiency, and preoperative pulmonary 
TABLE 2. Incremental risk factors for all-cause mortality after development of ventilatory dependency

\begin{tabular}{|c|c|c|c|}
\hline Risk factor & Coefficient \pm SE & $\boldsymbol{P}$ & $\begin{array}{c}\text { Reliability } \\
(\%)^{*}\end{array}$ \\
\hline \multicolumn{4}{|l|}{ Early hazard phase } \\
\hline Lower cardiac index & $-0.35 \pm 0.095$ & .0002 & 89 \\
\hline Higher PPA, diastolic $†$ & $0.19 \pm 0.078$ & .02 & 61 \\
\hline $\begin{array}{l}\text { Longer aortic clamp } \\
\text { time } \neq\end{array}$ & $0.062 \pm 0.034$ & .07 & 60 \\
\hline Lower $\mathrm{HCO}_{3}^{-} \S$ & $1.8 \pm 0.39$ & $<.0001$ & 84 \\
\hline Lower tidal volume\| & $1.2 \pm 0.24$ & $<.0001$ & 62 \\
\hline $\begin{array}{l}\text { Lidocaine use on } \\
\text { POD } 1\end{array}$ & $0.58 \pm 0.18$ & .001 & 60 \\
\hline $\begin{array}{l}\text { Vasopressin use on } \\
\text { POD } 1\end{array}$ & $0.62 \pm 0.18$ & .0004 & 64 \\
\hline $\begin{array}{l}\text { Longer interval from } \\
\text { extubation to first } \\
\text { reintubation }\end{array}$ & $0.0018 \pm 0.00065$ & .005 & 62 \\
\hline Reintubation & $0.16 \pm 0.16$ & .3 & $-\emptyset$ \\
\hline \multicolumn{4}{|l|}{ Late hazard phase } \\
\hline Older age\# & $0.45 \pm 0.12$ & .0001 & 83 \\
\hline History of stroke & $0.45 \pm 0.24$ & .06 & 53 \\
\hline Preoperative dialysis & $1.8 \pm 0.34$ & $<.0001$ & 74 \\
\hline Higher $\mathrm{PaCO}_{2}^{* *}$ & $0.99 \pm 0.32$ & .002 & 59 \\
\hline $\begin{array}{l}\text { Longer interval from } \\
\text { extubation to first } \\
\text { reintubation }\end{array}$ & $0.29 \pm 0.12$ & .01 & 88 \\
\hline Reintubation & $-0.88 \pm 0.49$ & .07 & $-\emptyset$ \\
\hline
\end{tabular}

$P P A$, pulmonary artery pressure; $P O D$, postoperative day; $S E$, standard error. *Frequency of occurrence in bootstrap bagging. †(PPA diastolic/20) ${ }^{2}$, squared transformation. $\ \mathrm{Ln}$ (aortic clamp time/80), logarithmic transformation. $\$ 25 / \mathrm{HCO}_{3}^{-}$, inverse transformation. $\| 800 /$ tidal volume, inverse transformation. १Forced in. \#Exp(age/50), exponential transformation. ${ }^{* *}\left(\mathrm{PaCO}_{2} / 40\right)^{2}$, squared transformation.

dysfunction also interact and affect survival after ventilatory dependency has developed. In this context, tracheostomy is not a lifesaving intervention; rather, it appears to be a marker for patients less likely to recover from their ventilatory dependency. ${ }^{8}$

Prevalence. Prevalence of ventilatory dependency after cardiovascular surgery in this series was within the range reported by others, ${ }^{7,16,17}$ varying from $3 \%$ to $22 \%$. This wide variability is in large part attributable to the discrepant definitions of ventilatory dependency in the literature. The 72 hours of cumulative intubation ${ }^{16}$ used in this study to define ventilatory dependency was believed to provide ample time for expected convalescence, even after complex operations involving systemic hypothermia and circulatory arrest. Application of STS guidelines (48 hours of intubation) would have led to a considerably larger and more heterogeneous patient population.

Decline in prevalence of ventilatory dependency in this study is a continuation of a trend apparent from previous studies from our institution. ${ }^{18-20}$ It is surprising that this

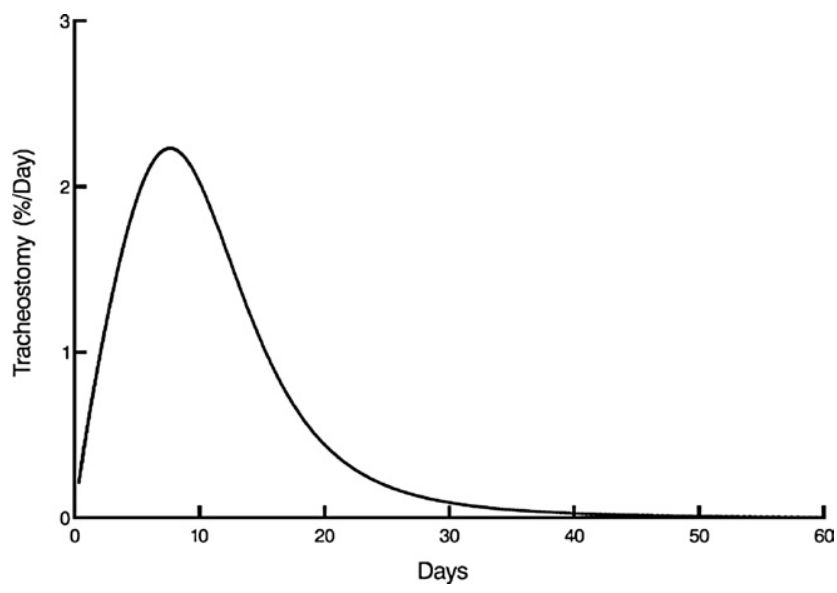

Figure 3. Timing of tracheostomy after onset of ventilatory dependency.

decline has occurred in the face of increasing complexity and acuity of illness. ${ }^{21-23}$ Because early cardiac function appears to be of critical importance, perhaps strategies developed to preserve myocardial function and minimize hemodynamic instability help explain this. Intraoperative myocardial protection has become increasingly more sophisticated, routine intraoperative echocardiography has reduced air embolism and arterioembolism, and cardiopulmonary bypass has been refined. In addition, collaborative management of heart failure has developed to include judicious use of intra-aortic balloon pumps, newer pharmacologic agents, and adherence to multidisciplinary management algorithms.

Risk factors. A strategy was developed to identify risk factors sequentially for ventilatory dependency based tem-

TABLE 3. Factors predictive of time to tracheostomy in patients with ventilatory dependency

\begin{tabular}{|c|c|c|c|}
\hline Factor & Coefficient \pm SE & $\boldsymbol{P}$ & $\begin{array}{c}\text { Reliability } \\
(\%)^{*}\end{array}$ \\
\hline \multicolumn{4}{|l|}{ Demography } \\
\hline Older age $†$ & $0.37 \pm 0.095$ & $<.0001$ & 77 \\
\hline \multicolumn{4}{|l|}{ Noncardiac comorbidity } \\
\hline COPD & $0.504 \pm 0.18$ & .005 & 60 \\
\hline $\begin{array}{l}\text { Higher preoperative } \\
\text { BUN } \ddagger\end{array}$ & $0.87 \pm 0.29$ & .002 & 60 \\
\hline $\begin{array}{l}\text { Lower preoperative } \\
\text { BUN§ }\end{array}$ & $0.88 \pm 0.22$ & $<.0001$ & \\
\hline \multicolumn{4}{|l|}{ Operative } \\
\hline Longer CPB time & $0.0021 \pm 0.00084$ & .01 & 85 \\
\hline
\end{tabular}

$B U N$, Blood urea nitrogen; $C O P D$, chronic obstructive pulmonary disease; $C P B$, cardiopulmonary bypass; $S E$, standard error. *Frequency of occurrence in bootstrap bagging. $†$ Exp(age/50), exponential transformation. $\ddagger \operatorname{Ln}(B U N)$, logarithmic transformation. §25/BUN, inverse transformation. 


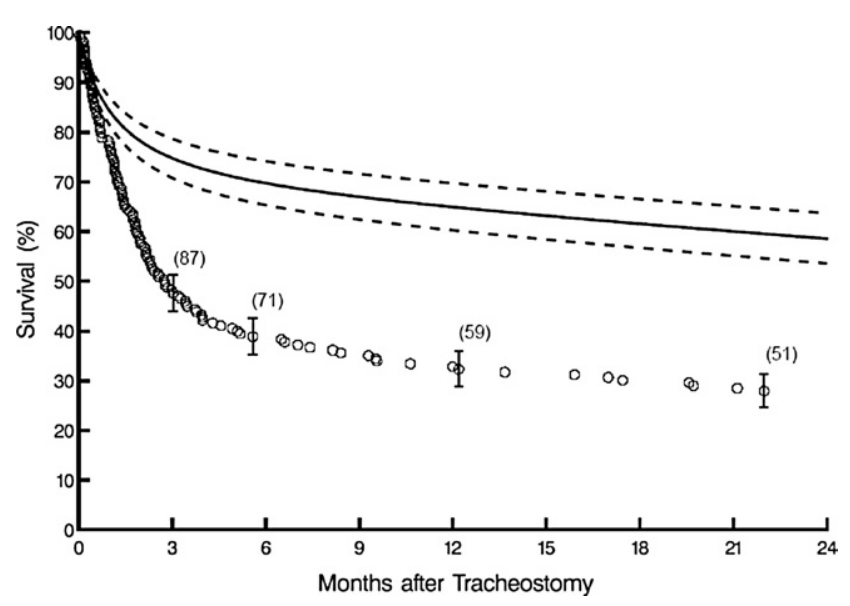

Figure 4. Observed (open circles) versus predicted (solid line enclosed within dashed $68 \%$ CLs) survival after tracheostomy.

porally on preoperative, operative, and early postoperative conditions, plus interim events, to find the most sensitive predictors and determine whether preoperative prediction was accurate. The rapidly changing condition of the patient (both worsening and improving) made preoperative modeling much less reliable than models generated from variables representing condition closer to the actual event of ventilatory dependency. This is not surprising in light of our companion study of risk factors for survival after tracheostomy, in which data pertaining to the events leading up to tracheostomy were the most predictive of outcome. ${ }^{8}$

Most risk factors for ventilatory dependency reflect early primary myocardial dysfunction and hemodynamic instability, both preoperatively and, more important, postoperatively. This is similar to the findings of others and previous reports from this institution. ${ }^{8,19,20}$ Jubran and colleagues ${ }^{24}$ have identified an association between myocardial function and successful weaning from mechanical ventilatory support, demonstrating that failure to wean was less related to gas exchange than to the heart's inability to meet increased demands accompanying spontaneous respiration.

Outcomes. Not surprisingly, mortality was high in patients experiencing ventilatory dependency. ${ }^{19}$ This may reflect our ability today to palliate ultimately unsalvageable patients beyond 72 hours, whereas previously, these same patients once died of acute cardiac failure shortly after their index operation. This is supported by our finding that risk factors for death, similarly to risk factors for ventilatory dependency, principally encompass variables related to myocardial dysfunction and hemodynamic instability.

It appears as though ventilatory dependency precipitates, follows, or is concurrent with a cascade of morbid events, ultimately resulting in multisystem organ failure and death. For patients surviving the early postoperative period, noncardiac comorbidities eventually become more important.
Impact of tracheostomy. About a fifth of our patients with ventilatory dependency underwent tracheostomy. They appeared to have weathered the initial operative insult and demonstrated sufficient hemodynamic stability to be considered for tracheostomy. Nevertheless, a number of events between operation and tracheostomy interceded. ${ }^{8}$ The cumulative effect of ventilatory dependency and these additional complications appeared to reduce survival after tracheostomy compared with that predicted without knowledge of these interim events occurring after the index operation. Because the postoperative course before tracheostomy so dramatically influences outcome thereafter, algorithms to guide tracheostomy as a salvage intervention have been difficult to generate. Unfortunately, decision for tracheostomy cannot currently be made on the basis of a potential survival advantage, but rather must be made for other indications, such as airway preservation, improved pulmonary toilet, ease of nursing care, and facilitation of patient mobilization. ${ }^{8}$

\section{Limitations}

This is a single-institution study. However, in contrast to other studies, it provides information about long-term survival of patients experiencing ventilatory dependency and, by means of competing risks analysis, the impact of tracheostomy. For some early postoperative events, it is difficult to say whether they accompanied ventilatory dependency or contributed to it. Use of inotropic and vasoactive agents is confounded by protocols specific to this institution. It is institutional policy to minimize use of these agents, and this may magnify their association with ventilatory dependency. We appreciate that these protocols may vary in other settings.

\section{Conclusions}

Continued improvement in operative and postoperative strategies to preserve myocardial function and stabilize hemodynamics after cardiovascular surgery should decrease the prevalence of ventilatory dependency. Preoperative models of ventilatory dependency are currently too insensitive for clinical use. Tracheostomy for ventilatory dependency and its outcome are poorly predicted, highlighting the complex interaction of events altering the patient's condition before and after tracheostomy.

We thank Marvin Leventhal and Angela York for data management, Songhua Lin for statistical programming, and Lucinda Mitchin and Tess Parry for editorial assistance.

\section{References}

1. Hedley-Whyte J, Corning H, Laver MB, Austen WG, Bendixen HH. Pulmonary ventilation-perfusion relations after heart valve replacement or repair in man. J Clin Invest. 1965;44:406-16.

2. McLennan JR, Young WE, Sykes MK. Respiratory changes after open-heart surgery. Thorax. 1965;20:545. 
3. Rea HH, Harris EA, Seelye ER, Whitlock RM, Withy SJ. The effects of cardiopulmonary bypass upon pulmonary gas exchange. $J$ Thorac Cardiovasc Surg. 1978;75:104-20.

4. LoCicero J 3rd, McCann B, Massad M, Joob AW. Prolonged ventilatory support after open-heart surgery. Crit Care Med. 1992;20:990-2.

5. Habib RH, Zacharias A, Engoren M. Determinants of prolonged mechanical ventilation after coronary artery bypass grafting. Ann Thorac Surg. 1996;62:1164-71.

6. Gilston A. Prolonged mechanical ventilation after open heart surgery. Cleve Clin Q. 1981;48:233-6.

7. Kollef MH, Wragge T, Pasque C. Determinants of mortality and multiorgan dysfunction in cardiac surgery patients requiring prolonged mechanical ventilation. Chest. 1995;107:1395-401.

8. Walts PA, Murthy SC, Arroliga AC, Yared JP, Rajeswaran J, Rice TW, et al. Tracheostomy after cardiovascular surgery: an assessment of long-term outcome. J Thorac Cardiovasc Surg. 2006;131:830-7.

9. Engoren M, Buderer NF, Zacharias A, Habib RH. Variables predicting reintubation after cardiac surgical procedures. Ann Thorac Surg. 1999; 67:661-5.

10. Bando K, Sun K, Binford RS, Sharp TG. Determinants of longer duration of endotracheal intubation after adult cardiac operations. Ann Thorac Surg. 1997;63:1026-33.

11. Lauer MS, Blackstone EH, Young JB, Topol EJ. Cause of death in clinical research: time for a reassessment? J Am Coll Cardiol. 1999; 34:618-20.

12. Breiman L. Bagging predictors. Machine Learning. 1996;24:123-40.

13. Blackstone EH. Breaking down barriers: helpful breakthrough statistical methods you need to understand better. J Thorac Cardiovasc Surg. 2001;122:430-9.

14. Blackstone EH, Naftel DC, Turner ME Jr. The decomposition of time-varying hazard into phases, each incorporating a separate stream of concomitant information. J Am Stat Assoc. 1986;81:615-24.

15. Andersen PK, Borgan O, Gill RD, Keiding N. Statistical models based on counting processes. New York: Springer Verlag; 1995.
16. Canver CC, Chanda J. Intraoperative and postoperative risk factors for respiratory failure after coronary bypass. Ann Thorac Surg. 2003;75: 853-7; discussion 7-8.

17. Pappalardo F, Franco A, Landoni G, Cardano P, Zangrillo A, Alfieri O. Long-term outcome and quality of life of patients requiring prolonged mechanical ventilation after cardiac surgery. Eur J Cardiothorac Surg. 2004;25:548-52.

18. Rady MY, Ryan T. Perioperative predictors of extubation failure and the effect on clinical outcome after cardiac surgery. Crit Care Med. 1999;27:340-7.

19. Rady MY, Ryan T, Starr NJ. Early onset of acute pulmonary dysfunction after cardiovascular surgery: risk factors and clinical outcome. Crit Care Med. 1997;25:1831-9.

20. Rady MY, Ryan T, Starr NJ. Perioperative determinants of morbidity and mortality in elderly patients undergoing cardiac surgery. Crit Care Med. 1998;26:225-35.

21. Noyez L, Janssen DP, van Druten JA, Skotnicki SH, Lacquet LK Coronary bypass surgery: what is changing? Analysis of 3834 patients undergoing primary isolated myocardial revascularization. Eur $J$ Cardiothorac Surg. 1998;13:365-9.

22. Plume SK, O'Connor GT, Olmstead EM. As originally published in 1994: Changes in patients undergoing coronary artery bypass grafting: 1987-1990. Updated in 2000. Northern New England Cardiovascular Disease Study Group. Ann Thorac Surg. 2001;72:314-5.

23. Grover FL, Shroyer AL, Hammermeister K, Edwards FH, Ferguson TB Jr, Dziuban SW Jr, et al. A decade's experience with quality improvement in cardiac surgery using the Veterans Affairs and Society of Thoracic Surgeons national databases. Ann Surg. 2001;234:464-72; discussion 72-4.

24. Jubran A, Mathru M, Dries D, Tobin MJ. Continuous recordings of mixed venous oxygen saturation during weaning from mechanical ventilation and the ramifications thereof. Am J Respir Crit Care Med. 1998;158:1763-9. 


\section{Appendix E1: Variables Available for Analysis Preoperative}

Demography. Sex, age at operation (y), height $(\mathrm{cm})$, weight $(\mathrm{kg})$, body surface area $\left(\mathrm{m}^{2}\right)$, body mass index $\left(\mathrm{kg} \cdot \mathrm{m}^{-2}\right)$.

Clinical condition. NYHA functional class (I-IV), Canadian angina class (0-4), emergency operation.

Cardiac status. Left ventricular dysfunction (grade), left ventricular ejection fraction (\%), electrocardiogram infarction, previous myocardial infarction.

Cardiac comorbidity. Pulmonary hypertension; number of previous cardiovascular operations; number of coronary artery systems diseased ( $\geq 50 \%$ stenosis); $\geq 50 \%$ and $\geq 70 \%$ stenoses of left main coronary artery, left anterior descending coronary artery, circumflex coronary artery, right coronary artery; atrial fibrillation/ flutter; complete heart block/pacer; ventricular arrhythmia; endocarditis; previous cardiac operation.

Noncardiac comorbidity. Serum albumin $\left(\mathrm{g} \cdot \mathrm{dL}^{-1}\right)$, blood urea nitrogen $\left(\mathrm{mg} \cdot \mathrm{dL}^{-1}\right)$, creatinine $\left(\mathrm{mg} \cdot \mathrm{dL}^{-1}\right)$, creatinine clearance $\left(\mathrm{mL} \cdot \mathrm{min}^{-1}\right)$, glomerular filtration rate $\left(\mathrm{mL} \cdot \mathrm{min}^{-1}\right)$, bilirubin $\left(\mathrm{mg} \cdot \mathrm{dL}^{-1}\right)$, hematocrit $(\%)$, chronic obstructive pulmonary disease, history of heart failure, hypertension, history of smoking, stroke, diabetes (diet controlled, oral hypoglycemic treated, insulin treated), dysrhythmia, peripheral arterial disease, carotid disease, popliteal disease, renal disease.

\section{Intraoperative}

Resting hemodynamics at anesthesia induction. Heart rate (beats $\left.\cdot \min ^{-1}\right)$, mean arterial pressure $(\mathrm{mm} \mathrm{Hg})$, pulmonary artery diastolic pressure $(\mathrm{mm} \mathrm{Hg}$ ), pulmonary artery systolic pressure $(\mathrm{mm} \mathrm{Hg})$, cardiac output $\left(\mathrm{L} \cdot \mathrm{min}^{-1}\right)$, cardiac index $\left(\mathrm{L} \cdot \min ^{-1} \cdot \mathrm{m}^{-2}\right)$.

Procedure. Coronary artery bypass grafting, aortic valve replacement, mitral valve repair, mitral valve replacement, thoracic aortic surgery, cardiopulmonary bypass time (min), aortic clamp time (min).

Experience. Date of operation (years since January 1, 1998).

\section{On Admission to ICU}

Cardiac status. Cardiac output $\left(\mathrm{L} \cdot \mathrm{min}^{-1}\right)$, cardiac index $(\mathrm{L}$. $\left.\min ^{-1} \cdot \mathrm{m}^{-2}\right)$, central venous pressure $(\mathrm{mm} \mathrm{Hg}$ ), heart rate (beats $\left.\cdot \min ^{-1}\right)$, pulmonary artery diastolic pressure $(\mathrm{mm} \mathrm{Hg}$ ), pulmonary artery systolic pressure $(\mathrm{mm} \mathrm{Hg})$, mean systemic arterial pressure (mm $\mathrm{Hg})$.

Respiratory status. Ventilatory rate (breaths $\cdot \min ^{-1}$ ), ventilatory support (mode), positive end-expiratory pressure $\left(\mathrm{cm} \mathrm{H}_{2} \mathrm{O}\right)$, tidal volume $(\mathrm{L})$, minute volume $\left(\mathrm{L} \cdot \mathrm{min}^{-1}\right), \mathrm{FIO}_{2}$, core temperature $\left({ }^{\circ} \mathrm{C}\right), \mathrm{pH}, \mathrm{PaCO}_{2}, \mathrm{PaO}_{2}, \mathrm{HCO}_{3}^{-}$, positive end-expiratory pressure $\left(\mathrm{cm} \mathrm{H}_{2} \mathrm{O}\right), \mathrm{pH}$.

Medications given in ICU (first 24 hours). Amiodarone, dobutamine, epinephrine, lidocaine, milrinone, norepinephrine, phenylephrine, vasopressin.

Interim events between operation and ventilatory dependency. Reoperation for bleeding, stroke, myocardial infarction, septicemia/ bacteremia, sepsis, renal failure.

\section{Appendix E2: Competing Risks of Death and Tracheostomy}

Because death removes patients from risk for tracheostomy, true prevalence of tracheostomy is not the same as probability of receiving a tracheostomy. Thus, the 2 driving forces, hazard functions for death and tracheostomy, were allowed to act simultaneously from onset of ventilatory dependency to determine the proportions of patients receiving tracheostomy and dead as a function of time (Figure E4, A). The proportion of patients receiving tracheostomy was approximately $20 \%$, about balanced early after onset of pulmonary failure by death before tracheostomy; however, thereafter there were continuing deaths, such that by 2 years, more than a third of patients were dead (Figure E4, $B$ ).

These figures, however, are only averages. Figure E5, $A$, depicts a low-risk patient and Figure E5, $B$, a high-risk patient to illustrate the interplay between death and tracheostomy. 
TABLE E1-A. Characteristics of patients, details of procedures, ICU admission data, and interim events (categorical variables)

\begin{tabular}{|c|c|c|c|c|c|}
\hline \multirow[b]{3}{*}{ Characteristic } & \multicolumn{4}{|c|}{ Ventilatory dependency } & \multirow[b]{3}{*}{$\boldsymbol{P}$} \\
\hline & \multicolumn{2}{|r|}{ With } & \multicolumn{2}{|r|}{ Without } & \\
\hline & $\mathrm{n}^{*}$ & No. $(\%$ of $704 \mathrm{t})$ & $\mathbf{n}^{*}$ & No. $(\%$ of $12,073+)$ & \\
\hline Male & 704 & $409(58)$ & 12,073 & $8,387(69)$ & $<.0001$ \\
\hline \multicolumn{6}{|l|}{ Clinical status } \\
\hline \multicolumn{6}{|l|}{ Cardiac morbidity } \\
\hline Previous myocardial infarction & 704 & $375(56)$ & 12,071 & $5,274(44)$ & $<.0001$ \\
\hline LV dysfunction grade & 537 & & 10,578 & & $<.0001$ \\
\hline None & & $244(45)$ & & $6,320(60)$ & \\
\hline Mild & & $103(19)$ & & $1,898(18)$ & \\
\hline Moderate & & $90(17)$ & & $1,330(13)$ & \\
\hline \multicolumn{6}{|l|}{ Noncardiac comorbidity } \\
\hline COPD & 704 & $245(35)$ & 12,071 & $2,681(22)$ & $<.0001$ \\
\hline Smoking history & 679 & $461(68)$ & 11,717 & $7,195(61)$ & .0007 \\
\hline PAD & 704 & $376(53)$ & 12,072 & 4,542 (38) & $<.0001$ \\
\hline Diabetes & 686 & $227(33)$ & 11,807 & $3,006(26)$ & $<.0001$ \\
\hline Insulin-treated & & $100(15)$ & & $1,015(8.6)$ & $<.0001$ \\
\hline Non-insulin-treated & & $127(19)$ & & $1,991(17)$ & .3 \\
\hline \multicolumn{6}{|l|}{ Procedure§ } \\
\hline Off-pump procedure & 704 & $38(5.4)$ & 12,073 & $1,123(9.3)$ & .0005 \\
\hline CABG & & $442(63)$ & & $7,776(64)$ & .4 \\
\hline Aortic valve surgery & & $246(35)$ & & $3,268(27)$ & $<.0001$ \\
\hline Dobutamine & & $43(6.1)$ & & $161(1.3)$ & $<.0001$ \\
\hline Interim events between ICU admission and ventilatory dependency & 704 & & 12,073 & & $<.0001$ \\
\hline Reoperation for bleeding & & $139(20)$ & & $316(2.6)$ & $<.0001$ \\
\hline Stroke & & $56(8.0)$ & & $88(0.73)$ & $<.0001$ \\
\hline Myocardial infarction & & $14(2.0)$ & & $47(0.39)$ & $<.0001$ \\
\hline Septicemia/bacteremia & & $28(4.0)$ & & $24(0.2)$ & $<.0001$ \\
\hline Sepsis & & $26(3.7)$ & & $4(0.03)$ & $<.0001$ \\
\hline Renal failure & & $58(8.2)$ & & $63(0.52)$ & $<.0001$ \\
\hline
\end{tabular}

$C A B G$, coronary artery bypass grafting; $C O P D$, chronic obstructive pulmonary disease; $I C U$, intensive care unit, $L V$, left ventricular; NYHA, New York Heart Association; $P A D$, peripheral arterial disease. *Number of values available for analysis. †Based on non-missing values. ‡lnstitutional designation used for reimbursement; largely represents patients in cardiogenic shock. §Not mutually exclusive. 
TABLE E1-B. Characteristics of patients, details of procedures, and ICU admission data (continuous variables)

\begin{tabular}{|c|c|c|c|c|c|}
\hline \multirow[b]{3}{*}{ Characteristic } & \multicolumn{4}{|c|}{ Ventilatory dependency } & \multirow[b]{3}{*}{$P$} \\
\hline & \multicolumn{2}{|c|}{ With $(n=704)$} & \multicolumn{2}{|c|}{ Without $(n=12,073)$} & \\
\hline & $\mathrm{n}^{*}$ & Mean \pm SD & $\mathrm{n}^{*}$ & Mean \pm SD & \\
\hline \multicolumn{6}{|l|}{ Demography } \\
\hline Age (y) & 704 & $64 \pm 13$ & 12,073 & $67 \pm 11$ & $<.0001$ \\
\hline BMI $\left(\mathrm{kg} \cdot \mathrm{m}^{-2}\right)$ & 703 & $28 \pm 5.4$ & 12,062 & $28 \pm 6.2$ & .9 \\
\hline \multicolumn{6}{|l|}{ Laboratory measurements } \\
\hline BUN (mg $\left.\cdot \mathrm{dL}^{-1}\right)$ & 681 & $20 \pm 11$ & 11,756 & $29 \pm 18$ & $<.0001$ \\
\hline Bilirubin $\left(\mathrm{mg} \cdot \mathrm{dL}^{-1}\right) \dagger$ & 541 & $0.6(0.4,1)$ & 9,058 & $0.6(0.4,1.4)$ & $<.0001$ \\
\hline Hematocrit $(\%)$ & 514 & $38 \pm 5.3$ & 8,778 & $34 \pm 6.1$ & $<.0001$ \\
\hline \multicolumn{6}{|l|}{ Preoperative hemodynamics } \\
\hline Heart rate (beats $\cdot \min ^{-1}$ ) & 704 & $80 \pm 18$ & 12,063 & $74 \pm 14$ & $<.0001$ \\
\hline Pcv (mm Hg) & 699 & $15 \pm 6.6$ & 12,035 & $12 \pm 5.0$ & $<.0001$ \\
\hline \multicolumn{6}{|l|}{ Intraoperative } \\
\hline Aortic clamp time (min) & 672 & $70 \pm 38$ & 11,941 & $91 \pm 47$ & $<.0001$ \\
\hline CPB time (min) & 704 & $93 \pm 48$ & 12,072 & $138 \pm 68$ & $<.0001$ \\
\hline \multicolumn{6}{|l|}{ At ICU admission } \\
\hline Ventilatory rate (breaths $\cdot \min ^{-1}$ ) & 702 & $9.4 \pm 2.5$ & 11,868 & $8.3 \pm 0.9$ & $<.0001$ \\
\hline Tidal volume $\left(\mathrm{mL} \cdot \mathrm{min}^{-1}\right)$ & 702 & $835 \pm 158$ & 11,868 & $882 \pm 133$ & $<.0001$ \\
\hline Minute volume (L) & 702 & $7.8 \pm 2.3$ & 11,868 & $7.3 \pm 1.29$ & $<.0001$ \\
\hline $\mathrm{pH}$ & 703 & $7.4 \pm 0.07$ & 12,051 & $7.4 \pm 0.06$ & $<.0001$ \\
\hline $\mathrm{PaCO}_{2}(\mathrm{~mm} \mathrm{Hg})$ & 703 & $41 \pm 6.4$ & 12,051 & $40 \pm 5.8$ & $<.0001$ \\
\hline $\mathrm{PaO}_{2}(\mathrm{~mm} \mathrm{Hg})$ & 703 & $152 \pm 73$ & 12,051 & $161 \pm 63$ & $<.0001$ \\
\hline $\mathrm{HCO}_{3}^{-}$ & 703 & $24 \pm 3.1$ & 12,051 & $25 \pm 2.4$ & $<.0001$ \\
\hline Core temperature $\left({ }^{\circ} \mathrm{C}\right)$ & 704 & $36 \pm 0.65$ & 12,062 & $36 \pm 0.8$ & $<.0001$ \\
\hline PpA, systolic (mm Hg) & 684 & $38 \pm 12$ & 10,399 & $32 \pm 10$ & $<.0001$ \\
\hline PPA, diastolic (mm Hg) & 684 & $20 \pm 6.6$ & 10,395 & $15 \pm 5.5$ & $<.0001$ \\
\hline Heart rate (beats $\cdot \min ^{-1}$ ) & 704 & $95 \pm 16$ & 12,003 & $87 \pm 13$ & $<.0001$ \\
\hline PA0, mean (mm Hg) & 704 & $79 \pm 13$ & 12,063 & $81 \pm 11$ & $<.0001$ \\
\hline Pcv $(\mathrm{mm} \mathrm{Hg})$ & 704 & $13 \pm 5.2$ & 12,037 & $10 \pm 4.1$ & $<.0001$ \\
\hline Cardiac index $\left(\mathrm{L} \cdot \mathrm{min}^{-1} \cdot \mathrm{m}^{-2}\right)$ & 704 & $2.6 \pm 0.73$ & 12,073 & $2.7 \pm 0.64$ & $<.001$ \\
\hline
\end{tabular}

$B M I$, Body mass index; $B U N$, blood urea nitrogen; $C P B$, cardiopulmonary bypass; $I C U$, intensive care unit; $P a o$, systemic arterial pressure; $P C V$, central venous pressure; $P P A$, pulmonary artery pressure; $S D$, standard deviation. *Number of values available for analysis. †Median (15th, 85th percentiles). 
TABLE E2. Incremental risk factors for death before tracheostomy in patients with ventilatory dependency

\begin{tabular}{|c|c|c|c|}
\hline Factor & Coefficient \pm SE & $\boldsymbol{P}$ & $\begin{array}{c}\text { Reliability } \\
(\%)^{*}\end{array}$ \\
\hline \multicolumn{4}{|l|}{ Early hazard phase } \\
\hline $\begin{array}{l}\text { Shorter aortic clamp time } \\
\text { Measurement on entry to } \\
\text { ICU }\end{array}$ & $-0.096 \pm 0.5$ & .06 & 81 \\
\hline Higher PPA, diastolic $†$ & $0.36 \pm 0.092$ & .0001 & 84 \\
\hline Lower Pao, mean $\ddagger$ & $1.29 \pm 0.38$ & .0007 & 80 \\
\hline Lower cardiac index & $-0.28 \pm 0.11$ & .01 & 60 \\
\hline Lower $\mathrm{HCO}_{3}^{-} \S$ & $1.92 \pm 0.42$ & $<.0001$ & 87 \\
\hline $\begin{array}{l}\text { Lower minute volume\| } \\
\text { Medications (first } 24 \mathrm{~h} \text { in } \\
\text { ICU) }\end{array}$ & $0.98 \pm 0.22$ & $<.0001$ & 86 \\
\hline Vasopressin & $0.86 \pm 0.19$ & $<.0001$ & 67 \\
\hline $\begin{array}{l}\text { Longer interval from } \\
\text { operation to } \\
\text { ventilatory } \\
\text { dependency? }\end{array}$ & $-0.70 \pm 0.25$ & .005 & 46 \\
\hline \multicolumn{4}{|l|}{ Late hazard phase } \\
\hline History of COPD & $0.79 \pm 0.27$ & .003 & 74 \\
\hline $\begin{array}{l}\text { Longer aortic clamp } \\
\text { time\# }\end{array}$ & $0.14 \pm 0.063$ & .03 & 57 \\
\hline Insulin-treated diabetes & $0.69 \pm 0.27$ & .01 & 80 \\
\hline Higher BUN** & $-0.42 \pm 0.22$ & .06 & 70 \\
\hline
\end{tabular}

$B U N$, blood urea nitrogen; $C O P D$, chronic obstructive pulmonary disease; $I C U$, intensive care unit; $P a O$, systemic arterial pressure; $P P A$, pulmonary artery pressure; $S E$, standard error. *Frequency of occurrence in bootstrap bagging. $\dagger\left(\mathrm{PPA}_{\mathrm{P}} \text { diastolic/20 }\right)^{2}$, squared transformation. $\ddagger(80 / \mathrm{PAO}$, mean), inverse transformation. $\S\left(25 / \mathrm{HCO}_{3}^{-}\right)$, inverse transformation. $\|(3,500 /$ minute volume), inverse transformation. $\$(72 /$ interval from operation to ventilatory dependency), inverse transformation. \#(Aortic clamp time/120) ${ }^{2}$, squared transformation. ${ }^{* *}(25 / \mathrm{BUN})$, inverse transformation.
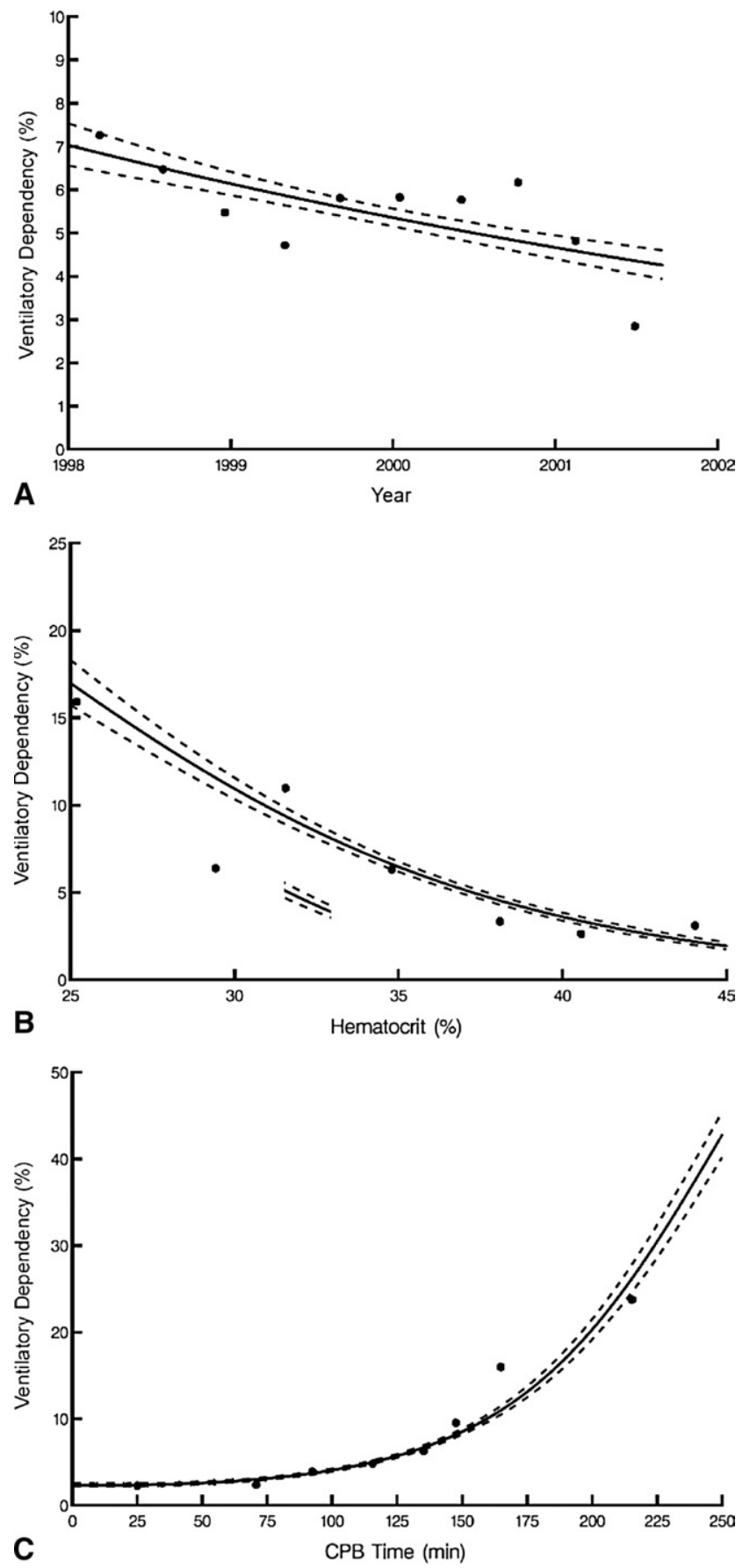

Figure E1. Relationship of various factors to postoperative ventilatory dependency. Closed circles represent summary data, and solid lines are trend lines enclosed within $68 \%$ confidence limits ( \pm 1 standard error). A, Date of operation. B, Preoperative hematocrit. C, Cardiopulmonary bypass (CPB) time. 
TABLE E3. Risk factors for ventilatory dependency: Preoperative model

\begin{tabular}{|c|c|c|c|}
\hline Risk factor & Coefficient \pm SE & $\boldsymbol{P}$ & $\begin{array}{c}\text { Reliability } \\
(\%)^{*}\end{array}$ \\
\hline \multicolumn{4}{|l|}{ Demography } \\
\hline Higher BMI $\left(\mathrm{kg} \cdot \mathrm{m}^{-2}\right) \dagger$ & $0.44 \pm 0.15$ & .003 & 88 \\
\hline \multicolumn{4}{|l|}{ Clinical status } \\
\hline NYHA class III/IV & $0.53 \pm 0.09$ & $<.0001$ & 99 \\
\hline Emergency operation & $2.3 \pm 0.15$ & $<.0001$ & 99 \\
\hline \multicolumn{4}{|l|}{ Cardiac morbidity } \\
\hline $\begin{array}{l}\text { Previous } \\
\text { cardiovascular } \\
\text { operation }\end{array}$ & $0.27 \pm 0.092$ & .003 & 58 \\
\hline $\begin{array}{l}\text { Previous myocardial } \\
\text { infarction }\end{array}$ & $0.39 \pm 0.092$ & $<.0001$ & 99 \\
\hline Previous heart failure & $0.26 \pm 0.103$ & .01 & 58 \\
\hline $\begin{array}{l}\text { Higher grade of } \\
\text { tricuspid valve } \\
\text { regurgitation }\end{array}$ & $0.22 \pm 0.039$ & $<.0001$ & 87 \\
\hline \multicolumn{4}{|l|}{ Noncardiac comorbidity } \\
\hline COPD & $0.32 \pm 0.0903$ & .0005 & 90 \\
\hline PAD & $0.39 \pm 0.09$ & $<.0001$ & 75 \\
\hline \multicolumn{4}{|l|}{ Higher BUN } \\
\hline BUN & $0.048 \pm 0.00904$ & $<.0001$ & \\
\hline BUN‡ & $-0.12 \pm 0.039$ & .003 & 99 \\
\hline Higher bilirubin & $0.14 \pm 0.053$ & .009 & \\
\hline \multicolumn{4}{|l|}{ Experience } \\
\hline $\begin{array}{c}\text { Earlier date of } \\
\text { operation }\end{array}$ & $-0.21 \pm 0.041$ & $<.0001$ & 98 \\
\hline \multicolumn{4}{|l|}{ Procedure } \\
\hline CABG & $-0.52 \pm 0.12$ & $<.0001$ & 84 \\
\hline$C A B G+A V$ surgery & $-0.56 \pm 0.18$ & .002 & 56 \\
\hline $\begin{array}{c}C A B G+\text { aorta } \\
\text { procedure }\end{array}$ & $1.2 \pm 0.31$ & $<.0001$ & 79 \\
\hline $\begin{array}{c}\mathrm{CABG}+\mathrm{AV} \text { surgery }+ \\
\text { aorta procedure }\end{array}$ & $0.74 \pm 0.24$ & .002 & 75 \\
\hline MV repair only & $-1.2 \pm 0.29$ & $<.0001$ & 95 \\
\hline $\begin{array}{l}\text { AV surgery }+\mathrm{MV} \\
\text { replacement }\end{array}$ & $0.71 \pm 0.25$ & .004 & 69 \\
\hline Aorta procedure only & $1.4 \pm 0.21$ & $<.0001$ & 96 \\
\hline
\end{tabular}

$A V$, Aortic valve; $B M I$, body mass index; $B U N$, blood urea nitrogen; $C A B G$, coronary artery bypass grafting; $C O P D$, chronic obstructive pulmonary disease; $M V$, mitral valve; NYHA, New York Heart Association; PAD, peripheral arterial disease; $S E$, standard error. *Frequency of occurrence in bootstrap bagging. $\dagger(B M I / 40)^{2}$, squared transformation. $\ddagger(B U N / 20)^{2}$, squared transformation.

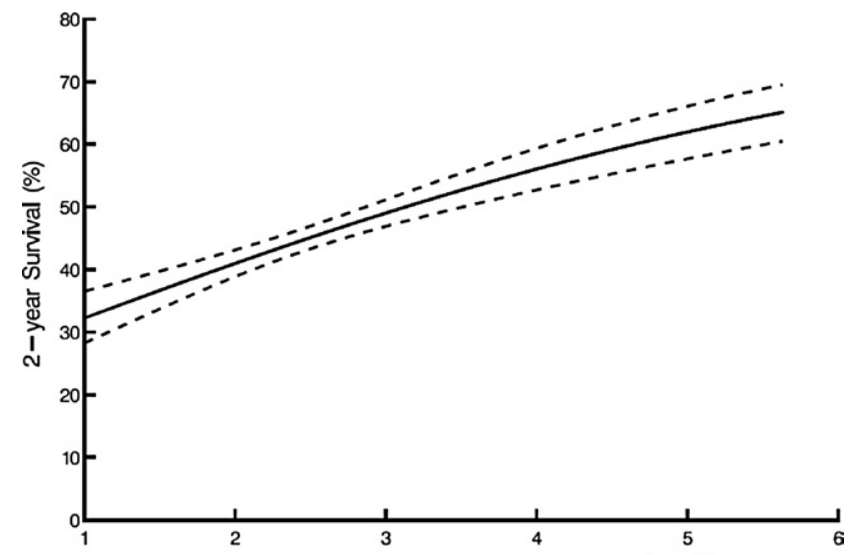

A Cardiac Index at ICU Admission $\left(\mathrm{L} \cdot \mathrm{min}^{-1} \cdot \mathrm{m}^{-2}\right)$

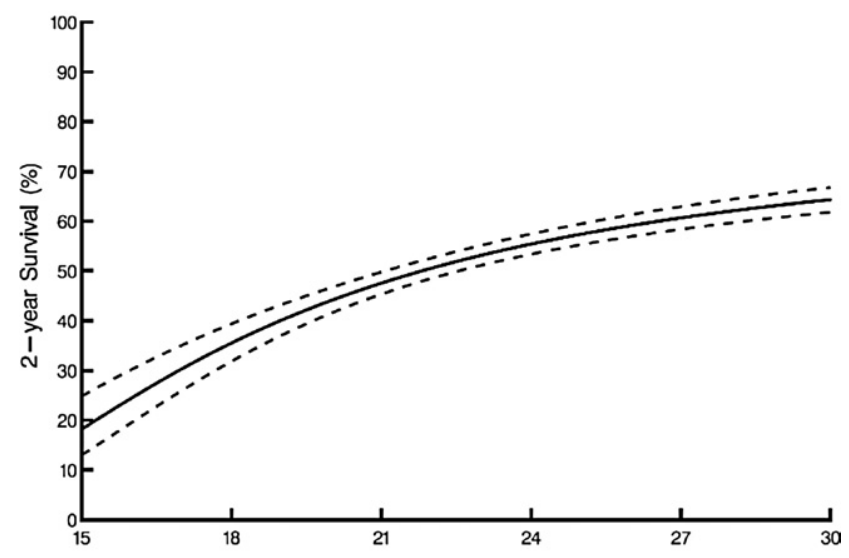

B

$\mathrm{HCO}_{3}^{-}$at ICU Admission $\left(\mu \mathrm{M} \cdot \mathrm{L}^{-1}\right)$

Figure E2. Univariable trends of risk factors with 2-year survival. A, Cardiac index at intensive care unit (ICU) admission. B, Acidosis at ICU admission.

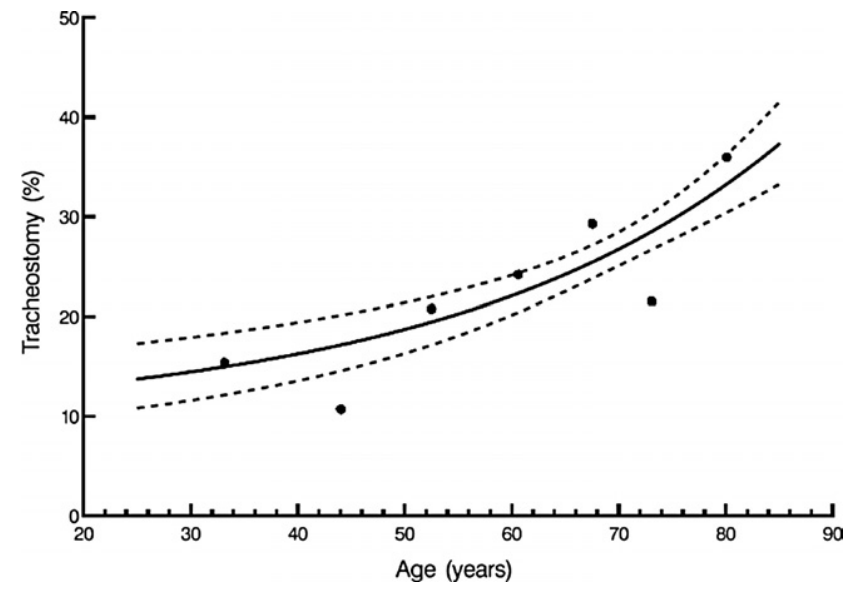

Figure E3. Relationship of age and timing of tracheostomy. 


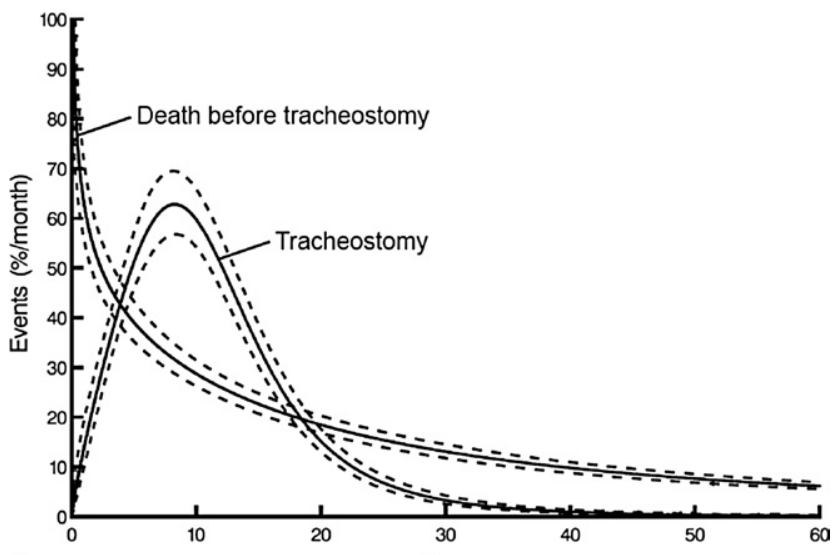

A

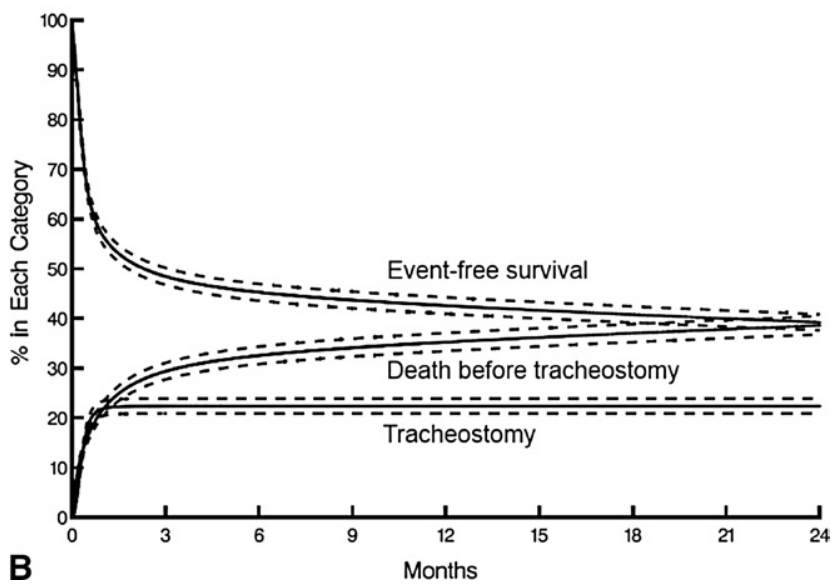

Figure E4. Instantaneous risk of events. A, Competing risks of death before tracheostomy and of undergoing tracheostomy among patients with ventilatory dependency. Time zero is $\mathbf{7 2}$ cumulative hours of intubation after cardiovascular surgery. B, Result of simultaneous risk of competing events on prevalence of each state. All patients start in the state "event-free survival" and migrate at rates shown in panel $A$ into "death before tracheostomy" or "tracheostomy."
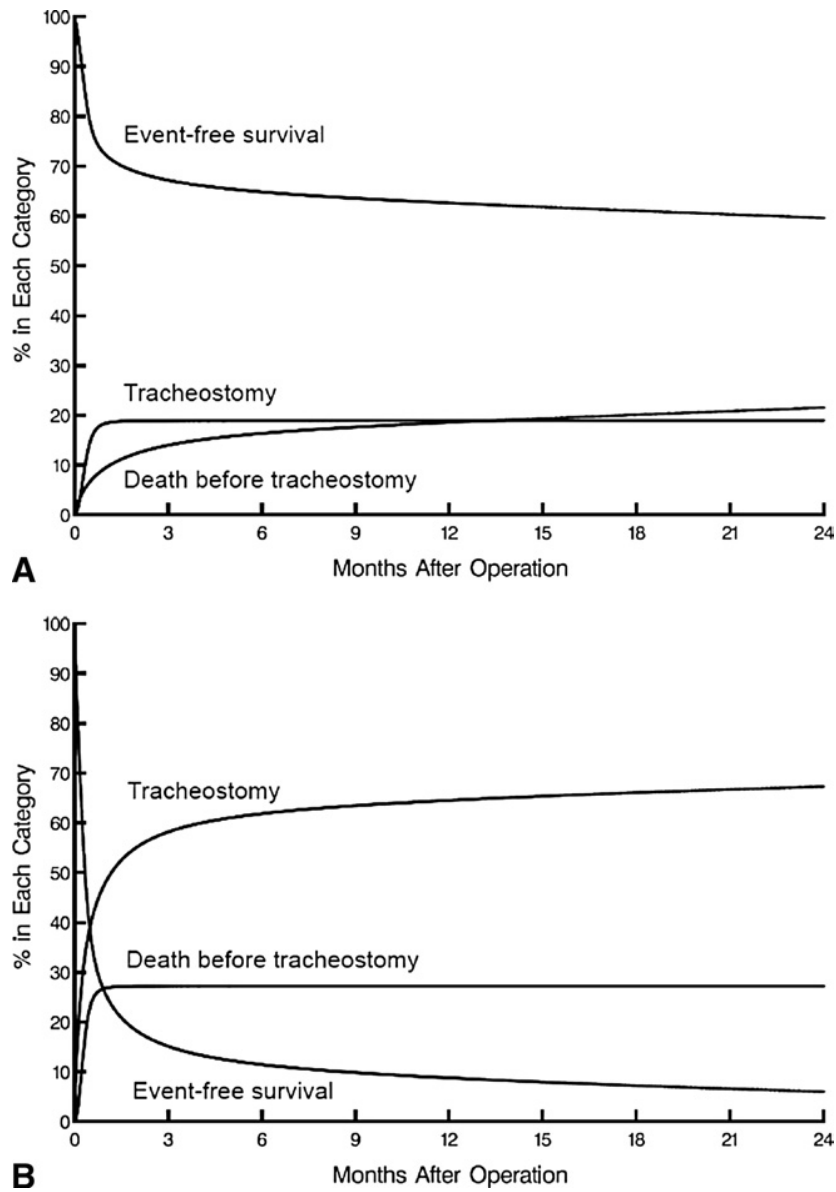

Figure E5. Predicted survival after developing ventilatory dependency, in the competing-risks format of Figure E4, B. A, Low-risk patient (see table). B, High-risk patient (see table).

\begin{tabular}{|c|c|c|}
\hline Low risk & & High risk \\
\hline 50 & Age (y) & 70 \\
\hline 80 & $\mathrm{PaO}_{2}(\mathrm{~mm} \mathrm{Hg})$ & 80 \\
\hline 15 & PPA, diastolic $(\mathrm{mm} \mathrm{Hg})$ & 20 \\
\hline 90 & Aortic clamp time (min) & 90 \\
\hline 110 & Total CPB time (min) & 200 \\
\hline 72 & $\begin{array}{l}\text { Interval from end of operation to } \\
\text { ventilatory dependency (h) }\end{array}$ & 200 \\
\hline 24 & $\mathrm{HCO}_{3}^{-}\left(\mathrm{mmol} \cdot \mathrm{L}^{-1}\right)$ & 23 \\
\hline 7,200 & Minute volume $\left(\mathrm{L} \cdot \mathrm{min}^{-1}\right)$ & 5,000 \\
\hline 3 & Cardiac index $\left(\mathrm{L} \cdot \min ^{-1} \cdot \mathrm{m}^{-2}\right)$ & 2.2 \\
\hline 16 & $\mathrm{BUN}\left(\mathrm{mg} \cdot \mathrm{dL}^{-1}\right)$ & 37 \\
\hline No & Insulin-treated diabetes & Yes \\
\hline No & Vasopressin & Yes \\
\hline No & Hypertension & Yes \\
\hline No & COPD & Yes \\
\hline
\end{tabular}

Values for variables used to simulate low- and high-risk patients. These values are used in multivariable equations, represented by Tables 2 and 3 , for all-cause mortality after development of ventilatory dependency and for time to tracheostomy. $B U N$, blood urea nitrogen; $C O P D$, chronic obstructive pulmonary disease; $C P B$, cardiopulmonary bypass. 